\title{
Tailor-made energy consulting for five different consumer groups
}

\author{
Learnings from the Austrian R\&D project "EnBe2.0" and the "EnBe2.0-Toolbox"
}

\author{
Bente Knoll (Author) \\ Büro für nachhaltige Kompetenz (Consultancy for \\ Sustainable Competence) B-NK GmbH, University of \\ Technology Vienna, University of Applied Sciences \\ Technikum Wien, Austria \\ Vienna, Austria \\ bente.knoll@b-nk.at \\ bente.knoll@tuwien.ac.at \\ knoll@technikum-wien.at
}

\author{
Georg Spreitzer (Author) \\ Büro für nachhaltige Kompetenz (Consultancy for Sustainable \\ Competence) B-NK GmbH, Wien, Austria \\ Vienna, Austria \\ spreitzer@b-nk.at \\ Christoph Göbl (Author) \\ OFI - Österreichisches Forschungsinstitut für Chemie und \\ Technik, \\ Wien, Austria \\ Vienna, Austria \\ christoph.goebl@ofi.at
}

\section{INTRODUCTION}

Abstract - Energy consulting for private homes can make a significant contribution to achieving energy efficiency targets. The success of energy consulting, which means as much as that the consulting leads to real energy savings, depends not only on socioeconomic, environmental, structural and technical factors like income, climate or living space but also the consideration of people's habits, needs, preferences, values, attitudes etc. is substantial. Within the R\&D-project "EnBe2.0" an ICT-Tool for tailor-made energy consulting for private homes has been developed. The "EnBe2.0-Toolbox" meets the multifaceted requirements of enduse energy consumers and assists energy consultants with targetgroup orientated energy consulting practices. The EnBe2.0Toolbox combines socio-scientific and technological knowledge and forms an interdisciplinary decision and communication supporting tool. On the one hand it provides the basics for targetgroup oriented communication and on the other hand it supports energy consultants to select customized energy saving actions. With the help of the toolbox, its pre-selected actions based on the customers' needs and its concrete suggestions how to carry out a target-group oriented communication and its provided example sentences energy consultants get a useful tool for their consulting practice. The toolbox supports to communicate selected measures in a way that directly addresses the advised person and hence leads to higher actual energy savings. This paper gives an overview about the functionality of the EnBe2.0-Toolbox and highlights the target group orientated communication.

Index Terms - energy consulting, energy use, consulting tool, private households, sustainability, interdisciplinary

\section{A. Current legal situation in Austria}

Due to the Austrian energy efficiency law, improving energy use behaviour of private households - for instance through energy consulting - has become an increasingly important topic on the Austrian policy agenda. To achieve more energy savings with the help of energy consulting the R\&D-project "EnBe2.0" was launched and has been carried out by an interdisciplinary consortium in Austria. The aim of the project EnBe2.0 is to develop an energy saving tool (EnBe2.0-Toolbox) that meets the multifaceted requirements of end-use energy consumers and assists energy consultants with target-group orientated energy consulting practices for private households [9].

Based on various research and practical observations, the project team has further developed the EnBe2.0-Toolbox, a communication and decision support tool which assists energy consultants in terms of

- $\quad$ selecting appropriate energy saving actions for their clients and

- addressing them properly taking into account the principle of target group orientated communication.

As research has shown socio-economic factors and personal interests, needs and claims have a crucial impact on the energy behaviour and, hence, on the needs and possibilities to gain real energy savings through energy consulting $[1,6,16]$. When investigating decision making processes between cohabitants or family members on energy consumption, personal factors have shown not to be the only relevant criteria [2]. For example, diverse individual ambitions and beliefs concerning quality of life, 
household management, comfort and so forth affect the willingness to accept energy saving actions among housemates to a considerable extent [16]. Therefore, tailor-made energy consulting actions can be more acceptable as well as more effective, when considering social, behavioural, psychological, ethic and financial influences.

\section{B. Current practice in energy consulting in Austria}

Looking at the current situation, one has to state that an unsatisfactory level of energy savings has been achieved in the private household sector in Austria which might lead to a failure in achieving pre-defined energy efficiency targets. The Austrian energy efficiency law, which is based on EU directives and came into force in Austria on the $1^{\text {st }}$ of January 2015, stipulated that power supply companies have to implement energy efficiency measures for end-use energy consumers, such as private households. About 40 percent of the energy savings have to be realized in private households throughout measures, such as connecting households to the district heat network, installation of smart meters or through energy consulting [4]. These circumstances lead to a major challenge for power supply companies and their energy consultants as well as for the other organisations and consultants providing energy consulting.

Within the existing trainings for energy consultants in Austria, neither household nor customer related factors are effectively considered. Aspects such as current living conditions, individual preferences, behavioural patterns, perceptions of life and lifestyles, beliefs of comfort or cosiness, as well as other personal and social issues are usually underestimated. As a consequence, a set of rather unspecific, inadequate and un-personalized energy saving actions have only lead to missed opportunities for achieving real energy savings.

This paper provides an overview on the results of the on-going Austrian R\&D-project "EnBe2.0 Tailor-made energy consulting for private households". In particular, the interdisciplinary components of the EnBE2.0-Toolbox and the underlying socio-scientific, empirical results regarding target group orientated communication of energy saving actions are discussed.

\section{THE AUSTRIAN R\&D-PROJECT ENBE2.0}

Based on the hypothesis that the common practice of energy consulting in Austria is insufficient when it comes to taking into account household and individual factors and, hence, inadequate real energy saving is gained, the research and development project EnBe2.0 was launched by OFI Technologie \& Innovation $\mathrm{GmbH}$ and Büro für nachhaltige Kompetenz (Consultancy for Sustainable Competence) B-NK GmbH. The interdisciplinary consortium, which combines gender expertise as well as socioscientific and technical knowledge, has been carrying out this research. The whole research and development process follows a bottom-up participation process with end-use energy consumers in private households and energy consultants. The project started in July 2014 and will be finalized in September 2016.
The project's overall aim is to provide a user-friendly, gender- and diversity-sensitive consulting tool which assists energy consultants by customizing energy saving actions and recommendations to the individual characteristics and needs of enduse energy consumers, who for their part, would perceive these measures as being viable and effective for their own daily living patterns. The outcome of the project EnBe2.0 is the implementation of the research results into a practical communication and decision support tool (EnBe2.0-Toolbox).

\section{THE ENBE2.0-TOOLBOX IN A NUTSHELL}

The EnBe2.0-Toolbox is a user-friendly, gender- and diversity-related decision and communication support system for energy consultants. It assists consultants to lower the energy demand in end-use energy consumers' private homes, through the linkage of 1) tailor-made selection of proper energy saving actions on a technical basis and 2) appropriate communication with the help of target group specific arguments and vocabulary.

The EnBe2.0-Toolbox is the result of a structured, interdisciplinary research and development approach and combines technical as well as social-scientific knowledge, regarding energy demand and energy use behaviour of customers in private homes. The EnBe2.0-Toolbox, as an instrument for energy consultants, reflects this interdisciplinary principle as it combines a technical database (energy saving measures) with social know how (how to address people properly). It is implemented as a comprehensive excel-spreadsheet and consists of two components - which can be applied separately - but more effectively are applied combined. In any case the total impact of the consultation is higher and therefore more real energy savings are gained, when the tailor-made selection of energy saving actions along technical-structural criteria is combined with a proper communication along the interests, values and attitude of the advised person.

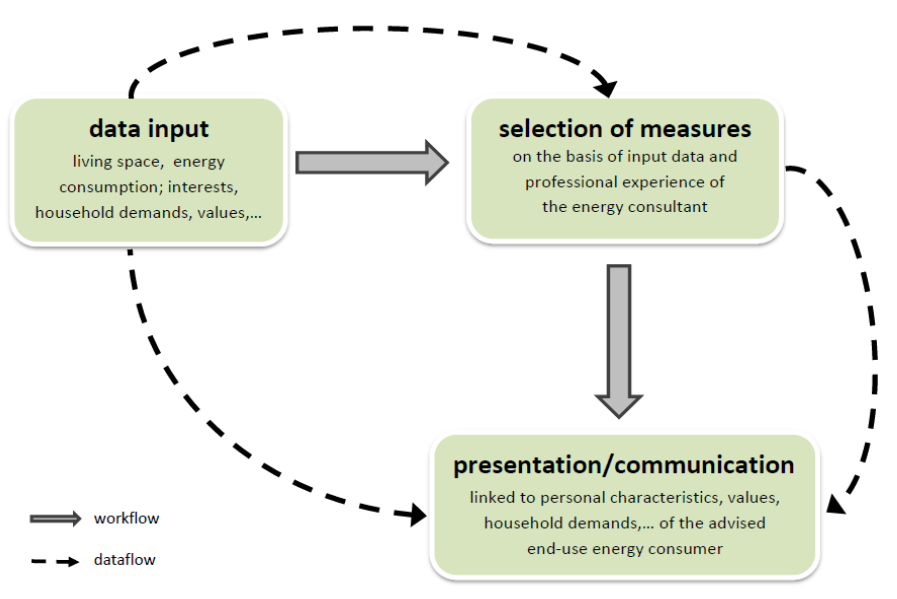

Fig.1: Main components of the EnBe2.0-Toolbox (B-NK \& OFI) 
The EnBe2.0-Toolbox assists the energy consultant to address their customers properly, as it suggests target-group orientated arguments, phrases and keywords. Therefore, with the help of empirical research and statistical analysis, five different target groups have been developed and the tool also helps to find out which of the five groups are more or less appropriate to describe the advised person and respectively suggests the related communication approaches.

\section{FOCUSSING ON PRIVATE HOUSEHOLDS}

Studies concerning the energy behavior of residents from various countries show that cultural factors influence the energy performance and effectiveness of energy saving measures. For instance, Norwegian households in general prefer a high number of lamps in a room to create a cozy atmosphere whereas Japanese households tend to prefer one light bulb placed in the ceiling [18]. Furthermore, through our literature review, we highlight a number of cultural differences concerning the importance of feedback about energy consumption and especially concerning the manner on how feedback is presented [5]. Studies show that citizens in the UK and Sweden have a high interest to compare their current rate of energy consumption with their own previous consumption habits. However, citizens of both countries are less interested in comparing their current habits with those of other households $[8,14]$. On the contrary, Japanese citizens are much more interested in comparing themselves with each other rather than with their own previous consumption habits [15]. Finnish citizens as well desire normative comparisons [7]. Another impressive finding was gained through the testing of four different designs of energy consumption by simply focusing on just two of the samples - one sample in the US and the other in Norway. The design that ranked highest in the US attained the least approval in Norway and was characterized as "childish", "unclear" and "difficult to interpret" [3,18].

In many cases, cultural background and socio-economic factors have shown to have an impact on energy use and consumption and, as a result, on the level of effectiveness provided by energy consultation. When investigating decision making processes between cohabitants or family members on energy consumption, personal factors have shown to not be the only relevant criteria [2]. For example, diverse individual ambitions and beliefs concerning quality of life, household management, comfort and so forth affect the willingness to accept energy saving measures among housemates to a considerable extent [16]. Therefore, tailor-made energy consulting measures can be more acceptable as well as more effective. Energy saving measures can only be achieved by considering a broad set of possible social, behavioral, psychological, ethnic and financial influences on household residents.

\section{Methodical Background of the EnBE2.0-ToOlboX}

In general, energy consumption is based on activities which are embedded in cultural, social, psychological and individual contexts [1]. The routines within the members of private households, in which energy consuming services are carried out, are highly relevant for the adoption of energy saving measures [13, 17]
Focusing on the acceptance and, hence, effectiveness of energy saving measures in private households, one main distinction can be made between the individual and the household perspective $[2,16]$. Both dimensions are relevant - at least for households with more than one person - since some energy saving measures can be implemented individually (e.g. duration of showering) while others may require arrangements between the household members (e.g. reducing room temperature, duration of lightning etc.). As literature review shows, behavioral change in energy-related concerns is more often investigated at the individual level than at the household level $[10,12]$.

Focusing on energy-relevant factors from an individual perspective, personal aspects gain more importance. Due to the fact that different psychological, behavioral, sociological theories are used, different approaches have been developed to categorize energy-related individual factors and therefore create various levels of classification. In regards to the energy-related household factors, as described above, we will neither discuss energy-related individual factors in detail in this paper, but rather provide an overview on some important pertaining aspects $[6,11,16]$ :

- Socio-demographic factors, such as gender, age, income, education etc.;

- Perceptions on life in general and the (individual) assumption on the quality of life;

- Values, tastes, needs, preferences and attitudes;

- Habits, manners, approaches and behavior;

- Knowledge, information, awareness, interests, possibilities of choice.

\section{A. Baseline Survey carried out within the EnBe2.0 project}

To investigate and characterize different types of households and their approach towards energy issues in general and to energy saving measures in particular, a quantitative online based survey among private household has been carried out $(n=541)$. We analyzed the data with the help of statistical methods like principal components analysis, factor analysis and linear regression. Based on the statistical analysis and on deepening qualitative interviews $(\mathrm{n}=15)$ among end-use energy consumers in private homes, as well as on literature review, experts' interviews and workshops with energy consultants, five energy consumer groups evolved.

The five groups differ from each other through their characteristics in the following categories:

- $\quad$ essential spheres of life

- values

- household requirements

- consumption preferences

- $\quad$ knowledge and attitude towards energy

For instance, one of the types is characterized as follows: education, knowledge, independence, autonomy, gainful employment and independence are important spheres of life. People of this type tend to be considerate, generous, environmentally and health-conscious, interested in technology and new media; they want their household primarily to be practical and clear as well 
as an area where people stay and to receive guests; concerning consumption environmental labels and energy efficiency classes are considered; implementing energy-saving measures is rather seen as troublesome.

Although the correlations are statistically significant, it is clear that the descriptions for each type are only tendencies and that overlaps occur. Nonetheless the five types can be differentiated well. In the En.Be2.0-Toolbox the types serve as a basis for target-group oriented communication of energy saving measures. Therefore, we have developed a set of target group specific arguments, phrases and keywords in terms of 'how to address people of a target-group properly', to raise real energy savings through energy consulting.

Figure 2 shows the main characteristics for the five consumer groups along these categories.

\section{B. Participatory approach when developing the EnBe2.0- Toolbox}

Field tests with energy consultants showed, that it may be to some extend 'misplaced' to ask this kind of 'personal questions' during an energy consultation. This risk can be obviated when the energy consultant feels confident concerning the use and the benefit of the EnBe2.0-Toolbox. For a pertinent effect, it is substantial, that the five questions and the use of the target group specific communication are implemented in the common practice of the energy consultant. Each energy consultant has a kind of individual common practice concerning how to proceed during the consultation. Preliminary results have shown that the use of the EnBe2.0-Toolbox enriches the consultation, independently from the individual approach of the energy consultant which they established so far.

\begin{tabular}{|c|c|c|}
\hline $\begin{array}{l}\text { knowledge- } \\
\text { driven } \\
\text { pragmatic } \\
\text { people }\end{array}$ & $\begin{array}{c}\text { considerate } \\
\text { community- } \\
\text { orientated people }\end{array}$ & $\begin{array}{l}\text { factual technology- } \\
\text { orientated people }\end{array}$ \\
\hline
\end{tabular}
environmental protection,

essential spheres of life

values, attitudes

$\begin{array}{ll} & \text { place of retreat, } \\ \text { lesser a place to } \\ \text { household } & \begin{array}{l}\text { represent } \\ \text { require- }\end{array} \\ \text { ments } & \text { themselves }\end{array}$

also important

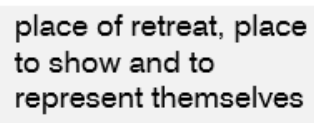

\section{Future issues,} climate change, holistic thinking, global responsibility education knowledge

\section{wellbeing-orientated people, who live in the here and now}
considerate, logical, interested in new things well-being, comfort liberty, fun

family, partnership, emotions, relationships

considerate, adapting the own behavior in favour of others technology

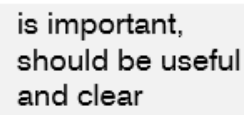

\section{is very important, inviting, comfortable, lounge area and place of retreat, feel comfortable together}

environmental and energy labels for consumption, technology and new media

\section{less important:} consumption, lifestyle, new media technology, technique

search for individual
solutions, not
spontaneously

technical requirements, new media, willing to spend money for entertainment electronics and technology

have existing knowledge about energy technology, deal with their own energy usage

Fig.2: Main characteristics of the five consumer groups for energy consulting in private homes 


\section{SUPPORTING TARGET-GROUP ORIENTATED COMMUNICATION}

The characteristics of the groups are the anchor for the target-group specific communication during the energy consultation. Using an example: Imagine that an energy consultant wants to communicate the importance of minimizing the standby electricity consumption to their client. Related to the consumer group the client belongs to, the communication process may differ like that:

A "holistic thinking environmentally aware" client may be told that, minimizing the standby consumption may be a small contribution on the global scale - but a contribution which everyone can do and which has an important impact in total - if lots of individual contributions are added up. This way of argumentation addresses the client's ear for holistic approaches and their awareness for responsibilities on a global scale.

In the contrary, a "open-minded wellbeing-orientated person, who lives here and now" may be told that, it is very easy to separate devices from the power grid and, hence, save energy. For example, with the help of remote controls or automatic timers it is quite comfortable to do so. In particular, if the separation is combined with the remote control of the plugged in device, e.g. the TV, the function has to be implemented only once and from then leads to energy savings without further effort.

This way of argumentation addresses the clients interest for comfort, new media and entertainment electronics.

\section{A. Which target-group is the most appropriate one?}

With the help of five pre-defined questions, which are asked by the energy consultant and are answered by the advised person, the EnBe2.0-Toolbox suggests, which of the five target groups is the most appropriate one to describe the client.
The questions are oriented to the categories, along which the five consumer resp. target groups are characterised. For example, one of the questions is 'Thinking of your home - what are your primary associations?'. The possible answers provided to that question are:

1) My home is first of all my private space to retreat from everyday stress.

2) My home is primarily an open place or lounge to receive guests.

3) My home is important to me, but I am not able to state which requirements mean the most to me.

4) My home is generally not so important to me.

The further questions to assign the customers to the most appropriate target group are:

- 'How high is your interest in technology, new media and technological innovations in general?'

- 'How important is environmental protection in your personal life?'

- 'How much money are you willing to pay for TV, computer, game consoles, sound systems or other entertainment electronics?'

- 'How strongly do you live your life according to your own, personal requirements?'

Each question has four answer options. In the aggregate, such can be calculated which of the target groups is more or less appropriate and, hence, which keywords, phrases and arguments can be seen as more compatible with the mind-set of the advised person.

Figure 3 shows how the suggested wordings and phrases for the most appropriate groups are presented in the EnBe2.0Toolbox. Further descriptions of the groups and related arguments can be requested on other subpages of the spreadsheet.

Which target-group is the most approp riate?

target group with highest priority

open-minded wellbeing-orientated people, who live in the here and now

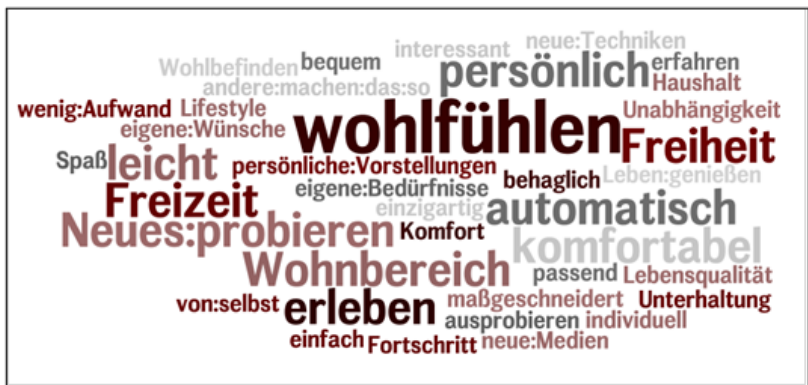

How to adress...

Energiesparen kann durchaus komfortabel sein ..

Es gibt viele ganz einfache Maßnahmen ...

... das kann ganz leicht umgesetzt werden

Mit Hilfe von Elektronik lässt sich einiges machen ... Kann man auch als etwas Neues sehen, das man ausprobiert ...

Fig.3: Screenshot of the EnBe2.0-Toolbox subpage "How to address the client properly" (partially in German) 


\section{SUPPORTING TARGET GROUP SPECIFIC ENERGY SAVING ACTIONS}

The technological component of the EnBe2.0-Toolbox is based on about 200 different energy saving actions and recommendations, that are assigned to the following 16 categories:

- Lightning
- Computer and office
- dishwasher
- white goods
- heating
- devices and gadgets
- cooling devices
- cooking

- mobility

- space cooling

- refurbishing

- standby

- dryer

- entertainment electronics

- hot water

- washing

On one hand this collection gives a good overview on the state of the art of energy consulting for private households and on the other hand it is the basis knowledge for every energy consultant. To obtain a broad overview of energy saving actions, various sources, such as scientific literature, experience of energy consultants, webpages of energy supply companies and others (klimaaktv.at, topprodukt.at etc.), scientific journals, information material for households and from specialised fairs and conventions were taken into account.

For new concepts and approaches, a so called "crazy ideas" approach was integrated in the collection. These actions are not typically used for a conventional energy consulting. However, with new and unconventional ideas and further development of existing actions, a lot of sustainable recommendations have been developed. To illustrate the following topics emerged by using the "crazy ideas"-approach:

- sharing of equipment (tools, cars, devices etc.)

- repairing and up cycling

- innovative control systems

- energy saving gadgets

In a first feedback-loop, collaborating energy consultants adapted and expanded the list of energy saving actions. In a next step, all actions were surveyed and evaluated concerning the following issues:

- Which actions are well accepted by private households?

- Which actions are poorly accepted by private households?

- Which actions are effective, from an energy consulting point of view?

After this evaluation, a prioritization of the actions was carried out. The result of this evaluation process is a categorized list of energy saving actions which serve as a basis of the EnBe2.0-Toolbox Technical Component.

To enable a sorting, an attribution regarding three different factors to every measure was necessary. These factors are:

- costs of the measure (How much will it cost to implement this measure?)
- investment action or behaviour modification (e.g. new refrigerator or lower room temperature)

- authorization (Is the authorization through other persons necessary? e.g. replacement of windows in a rented apartment)

According to the input data the energy-saving actions are selected (along costs, type of action, authorization) and get displayed as 'more suitable' for the advised person. The energy consultant has the possibility to adapt the selection, e.g. when the selection differs compared to their professional experience or compared to the estimated suitability of certain actions. Furthermore, the energy consultant has the possibility to add other actions, adapt already included actions and comment them. The results are strongly oriented on the customers' living circumstances and possibilities concerning the implementation of energy saving actions. At the end of the consulting process, the results can be handed to the client (printed in paper form) to support them by implementation and gaining real energy savings.

\section{SUMMARY \& OUTLOOK}

The EnBe2.0-Toolbox combines socio-scientific and technical components in an interdisciplinary ICT-tool to support decisions in the field of sustainability and energy efficiency. Both the selected actions and the connection points for target-group orientated communication, do strongly support the energy consultant. This facilitates to communicate selected measures in a way that directly addresses the advised person and, hence, leads to higher actual energy savings.

The EnBe2.0 project is still a work in progress. Currently, we do trainings and workshops for energy consultants, to implement the use of the EnBe2.0-Toolbox in their own common practice. In particular, to train the use of the target group specific communication formulations and to point out possibilities, how the five questions for the appropriation of the client can be raised within the common practice of the particular energy consultant. By all means it is substantial, that the energy consultant feels confident and hence can use the target group specific communication approach genuine.

As our research has shown so far, the use of the EnBe2.0Toolbox includes these benefits:

- benefit for advised person raises

- individual situation of client is strongly considered

- meet the clients at the place where they are

- appropriate communication leads to higher acceptance rates which itself leads to higher real energy savings

- satisfaction for energy consultant through higher success of consultation

The EnBe2.0-Toolbox as a result of an Austrian funded research and development project will be available in German language in the internet for free. The project and thus the EnBe2.0-Toolbox will be finalized in September 2016. At the conference in Amsterdam, at the end of August, we will be able to present final results. 


\section{ABOUT THE AUTHORS}

Dipl.-Ing. Dr. Bente Knoll works as a self-employed landscape and transport planner, consultant and social media designer. The focus of her professional work as managing director of Büro für nachhaltige Kompetenz (Consultancy for Sustainable Competence) B-NK GmbH is to integrate gender and diversity perspectives in urban and transport planning, architecture and mobility as well as in science and technology issues in general. Bente Knoll also holds various teaching assignments at Austrian universities in the field of Gender Studies and Engineering.

Dipl.-Ing. Christoph Göbl holds a Master Degree in Renewable Resources and a Bachelor Degree in Eco-Energy Engineering. He and works as project coordinator and researcher at OFI (Österreichisches Forschungsinstitut für Chemie und Technik). Energy Efficiency Consulting in the field of buildings and production plants and advisory activities with regard to the new Energy Efficiency Act are his main fields of work.

Dipl.-Ing. Georg Spreitzer holds a Master Degree in Environment and Bio-Resources Management and works as project coordinator and researcher at Büro für nachhaltige Kompetenz (Consultancy for Sustainable Competence) B-NK GmbH. His special interest is fostering sustainable development as well as empirical research using quantitative and qualitative methods.

\section{ACKNOWLEDGMENT}

The project is funded by the Austrian Research Promotion Agency (FFG) and the Federal Ministry of Transport, Innovation and Technology (BMVIT).

\section{REFERENCES}

[1] Aune, Margrethe 2007. Energy comes home. Energy Policy 35 (2007), pp. 5457-5465.

[2] Carlsson-Kanyama, Annika; Linden, Anna-Lisa, 2006. Energy efficiency in residences - Challenges for women and men in the north. Energy Policy 35 (2007), pp. 2163-2172.

[3] Egan, C., 1999. Graphical displays and comparative energy information: What do people understand and prefer? Paper presented at the Summer Study of the European Council for an Energy Efficient Economy, 1999, paper no. 2-12, http://www.eceee.org/conference_proceedings/eceee/1999/Panel _2/p2_12/ 07.10.2014.

[4] Energieeffizienzpaket des Bundes, 2014. Nationalratsbeschluss, http://www.bmwfw.gv.at/EnergieUndBergbau/Energieeffizienz/Documents/Beschluss\%20des\%20NR_182\%20der\%20Beilagen\%20XXV.\%20GP Energieeffienzpaket.pdf (08.10.2014)

[5] Fischer, Corinna, 2008. Feedback on household electricity consumption: a tool for saving energy? Energy Efficiency (2008), 1, pp. 79-104.

[6] Gareth, Morton; Nigel, Griffiths, 2012. Achieving energy efficiency through behavioural change - what does it take. Final report, Didcot: European Environment Agency.

[7] Haakana, M.; Sillanpää, L.; Talsi, M., 1997. The effect of feedback and focused advice on household energy consumption.
Paper presented at the Summer Study of the European Council for an Energy Efficient Economy, 1997.

[8] IEA, 2005. International Energy Agency demand-side management programme, Task XI: Time of use pricing and energy use for demand management delivery, Subtask 1 Report: Smaller customer energy saving by end use monitoring and feedback.

[9] Knoll, Bente; Spreitzer, Georg (2015): Tailor-made Energy Consulting for Private Households. The approach of the Austrian R\&D project "EnBe2.0". In: Vivian Kvist Johannsen, Stefan Jensen, Volker Wohlgemuth, Chris Preist und Elina Eriksson (Hg.): EnviroInfo \& ICT4S, Conference Proceedings: Atlantis Press, Amsterdam - Beijing - Paris. http://enviroinfo.eu/sites/default/files/pdfs/vol9073/0158.pdf (30.11.2015)

[10] Luitzenheiser, L., 1993. Social and behavioural aspects of energy use. Annual review of energy and the environment, 188, pp. 247289.

[11] Mayne, Ruth; Darby, Sarah; Hamilton, Jo, 2012. Individual and social influences on energy use. A literature review for the evaloc project, http://media.wix.com/ugd/caf2de_9ca788a582346d11201af07ba 0443ac3.pdf, 22.09.2014.

[12] McDougall, G.H.; Claxton, J.D.; Ritchie, J.R.; Anderson, C.D., 1981. Consumer energy research: a review. Journal of consumer research, 8, 3, pp. 343-354.

[13] Schwartz, Tobias; Stevens, Gunnar; Jakobi, Timo; Denef, Sebastian; Ramirez, Leonardo; Wulf, Volker; Randall, Dave, 2014. What People Do with Consumption Feedback: A LongTerm Living Lab Study of a Home Energy Management System. In: Interacting with computers. Oxford: The Oxford University Press.

[14] Sernhed, K.; Pyrko, J.; Abaravicius, J, 2003. Bill me this way!customer preferences regarding electricity bills in Sweden. In Proceedings of the 2003 summer study of the European Council for an energy efficient economy, pp. 1147-1150, Stockholm: ECEEE.

[15] Ueno, T.; Inada, R.; Saeki, O.; Tsuji, K, 2005. Effectiveness of displaying energy consumption data in residential houses. Analysis on how the residents respond. In Proceedings of the 2005 summer study of the European Council for an energy efficient economy, pp. 1289-1299, Stockholm: ECEEE.

[16] Uitdenbogerd, Diana, 2007. Energy and households: the acceptance of energy reduction options in relation to the performance and organisation of household activities. $\mathrm{PhD}$ thesis, Wageningen: Wageningen University.

[17] Whitmarsh, Lorraine, 2011. Social and psychological drivers of energy consumption behaviour and energy transition. In Dietz, S; Michie, J; Oughton, C. (ed.) The Political Economy of the Environment: An interdisciplinary approach, London: Routledge.

[18] Wilhite, H.; Høivik, A.; Olsen, J.G, 1999. Advances in the use of consumption feedback information in energy billing: The experiences of a Norwegian energy utility. Paper presented at the Summer Study of the European Council for an Energy Efficient Economy, 1999, paper no. 3-2.

[19] Wilhite, H.; Nakagami, H.; Masuda, T.; Yamaga, Y., 1996. A cross cultural analysis of household energy use behavior in Japan and Norway. Energy Policy 24(9), pp. 795-803. 